\title{
Can education change attitudes toward aging? A quasi-experimental design with a comparison group
}

\author{
Young-Shin Lee ${ }^{* 1}$, Seon-Hi Shin ${ }^{2}$, Philip A. Greiner ${ }^{1}$ \\ ${ }^{1}$ School of Nursing, San Diego State University, San Diego, United States \\ ${ }^{2}$ Measurement and Statistical Research Department, TEPS Center, Language Education Institute, Seoul National University, \\ Seoul, Korea
}

Received: March 23, 2015

Accepted: June 15, 2015

Online Published: June 23, 2015

DOI: $10.5430 /$ jnep.v5n9p90

URL: http://dx.doi.org/10.5430/jnep.v5n9p90

\begin{abstract}
Background: Widespread negative attitudes toward aging in the U.S. are obstacles to training care providers and providing high quality care. Studies identifying educational effects on attitudes toward older people are still inconclusive. Objective: To examine the impact of learning experiences on university student attitudes toward older people.

Methods: Design: A quasi-experimental design with a comparison group study. A total of 147 students registered in nursing and non-nursing programs completed three instruments measuring attitudes toward aging at three month intervals. All nursing students in the study were undertaking gerontology nursing course.

Results: All participants expressed more positive attitudes in direct measures than indirect measures. Nursing students taking this gerontology course had significantly lower negative attitudes and negative feelings toward older adults, lower anti-age bias, and improvement in pro-age bias over time as compared to non-nursing students.

Conclusions: The findings suggest that: 1) improved knowledge and clinical experience of aging reduce negative attitudes and are fundamental steps in developing positive attitudes for caring for older adults; and 2) comparative research using multiple measures provides a better understanding of attitudes toward older people.
\end{abstract}

Key Words: Attitudes, Age bias, Gerontology course, University students, Nursing

\section{INTRODUCTION}

Negative attitudes toward aging are obstacles to providing high quality care for the rapidly growing older population aged 65 years and older. Studies have reported widespread ageism and negative stereotyping of the elderly in the U.S. ${ }^{[1]}$ The attitudes of young students and men toward the aged are generally more negative than positive. ${ }^{[2-4]}$ Negative attitudes appear to influence undergraduates against working with older adults. ${ }^{[4,5]}$ Other studies similarly showed that negative attitudes toward the elderly among nursing students have affected students' work preferences. ${ }^{[6,7]}$
Attitudes are defined as a learned predisposition toward a target (object or person) that has been formed from previous experiences. For better understand the attitude concept, the Triadic Model of Attitudes, which is commonly used in social psychology has been applied. ${ }^{[8]}$ In the model, attitude consists of three components: Cognition (knowledge and belief), affect (feelings and emotion), and behavior. In the model, accuracy of knowledge and beliefs (cognition) is important because incorrect beliefs could lead to unpleasant consequences. Although cognition is most often evoked to justify an attitude, all three components are interdependent (see Fig-

\footnotetext{
*Correspondence: Young-Shin Lee; Email: ylee@mail.sdsu.edu; Address: School of Nursing, San Diego State University, 5500 Campanile Drive, San Diego, CA 92182, United States.
} 
ure 1). People develop pre-positioned views toward a target through social constructs and life experiences; these views remain relatively consistent over time and throughout various situations. ${ }^{[9]}$ Positive attitudes facilitate well-adjusted behaviors, while negative attitudes may lead to inappropriate behaviors. Previous studies of attitudes toward aging support the triadic model in that college students tend to derive their attitudes toward older adults from single or brief experiences in their homes or working environments. ${ }^{[10]}$ Nursing students who have interacted with ailing older adults are more likely to have negative attitudes toward aging than those who have experience with healthy, active older adults. ${ }^{[2,11]}$ Negative attitudes adversely affect efforts to train healthcare providers to work with older adults who may be perceived as highly demanding about their nursing care. ${ }^{[12]}$

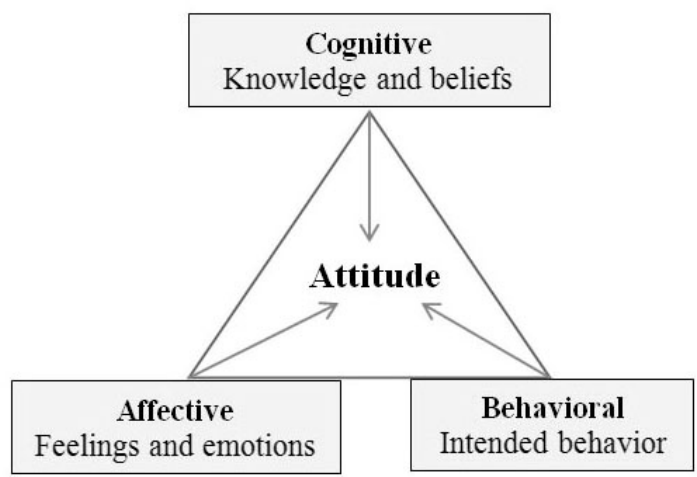

Figure 1. Triadic Model: Components of attitudes

Based on the Triadic Model, education and experience may impact the attitudes of young adults, but the effect of education in attitudes has not been well studied. In some cases, college students (nursing, medicine, pharmacy, and social work), who took a gerontology course improved their knowledge and developed positive attitudes toward aging, ${ }^{[13,14]}$ and had reduced negative attitudes toward aging. ${ }^{[15,16]}$ However, other studies concluded that educational experiences did not change nursing students' attitudes toward aging. ${ }^{[17,18]}$ As Olson ${ }^{[19]}$ reported, these inconsistent results may be related to the content of the curricula, which had low to moderate correlation with student attitudes toward aging and older adults.

Nursing students seem to have limited educational opportunities to develop positive attitudes toward the elderly. Because they are likely to meet sickly older adults in acute care facilities, their perceptions are often based on unwell and fragile older adults. ${ }^{[7,20]}$ This situation is similar to reports regarding nurses working in acute or long-term care settings, who develop negative attitudes toward older patients. ${ }^{[6,20,21]} \mathrm{Un}$ -

Published by Sciedu Press fortunately, one report showed that nearly half of nursing students never received specific information about aging as part of their education. ${ }^{[22]}$

Although American academic institutions made a decadelong, nationwide effort to improve gerontology competency in nursing curricula, ${ }^{[22]}$ research in attitudes towards aging and the effect of gerontology education was limited during that time. ${ }^{[5,6]}$ Therefore, the outcome remains inconclusive as to whether the effort had a positive effect on student attitudes. The inconclusive results might be due to the method of delivery of the gerontology content. ${ }^{[23]}$ Reports showed only $34 \%$ of nursing programs teach a gerontology course as a stand-alone course while the other schools infuse the content into other courses. ${ }^{[22,24]}$ Considering the definite shortage of nursing faculty in gerontology, integrating content with other courses might not deliver sufficient knowledge and skills of gerontology to a recommended level. ${ }^{[6]}$ Stand-alone gerontology courses focusing on specific content, taught by experienced faculty familiar with gerontology might be a better choice. ${ }^{[1]}$

Another reason for the inconclusive results can occur from a measurement issue of the concept. Thurston ${ }^{[25]}$ stated, "An attitude is a complex affair which cannot be wholly described by any single numerical index" (p. 550). To measure attitudes toward aging, a variety of instruments have been developed such as the Attitudes toward Older People Scale, ${ }^{[26]}$ the Facts on Aging Quiz, ${ }^{[27]}$ the Aging Semantic Differential, ${ }^{[28]}$ and the Fraboni Scale of Ageism. ${ }^{[29]}$ Most studies measuring attitudes toward aging used a single instrument; few studies used multiple instruments. In addition to the use of diverse measurements, previous studies of student attitudes toward aging applied a simple study design using a comparison group in a cross-sectional design. ${ }^{[4,14,18]}$ Others used pre- and post-tests in a single group. ${ }^{[11,17,30]}$ Based on current literature, comparison studies with prospective designs are still rare. A more refined study design may provide a better understanding of the phenomena.

The purpose of the current study was to test the hypothesis that exposure to objective and common views, experiences, and information regarding aging phenomena can change a student's perceptions, feelings, and behaviors toward older people and aging. Specific aims included: 1) describing positive and negative attitudes, feelings and bias toward aging, 2) identifying differences in the three aspects of attitudes between nursing and non-nursing students, and 3) determining whether students enrolled in a gerontology nursing course would change their attitudes toward older people in both positive and negative aspects over time, compared to students not enrolled in such a course. 


\section{METHODS}

\subsection{Sample and settings}

The proposed study was a quasi-experimental design with a comparison of the pre- and post-tests by nursing and nonnursing students. The study adhered to the protocol approved by the Institutional Review Board of the university data collection and publication. Recruitment began with students who registered for courses at a public university in California; those who registered in temporary or extended programs were excluded. A total of 147 students completed the study over one semester: The intervention (nursing) group comprised students taking a stand-alone gerontology course in the third of six semesters of the nursing program; the comparison (non-nursing) group comprised students pursuing other majors and not being enrolled in gerontology course in the same university. All the nursing students had experience with older adults during the fundamental and medical-surgical nursing courses in the prior semesters. The comparison group was the students registered in the same university, but not a nursing major. Both groups were not controlled their individual characteristics.

After receiving written consent from the participants, data were collected online by a survey and journal writings at the beginning and end of a semester. The web-based survey was created with the StatPac 10.1. ${ }^{[31]}$ All communication between the participants and the researcher was through emails; identities of participants were not disclosed. Email addresses were the only means of matching pre-and post-test scores and other communications.

\subsection{Educational exposure}

The nursing group took a stand-alone gerontology course offered in a baccalaureate nursing program. The three-hour course consisted of two credit hours of lecture and one credit hour of clinical work. Lectures were aimed at enhancing student knowledge of normal aging rather than pathological changes in aging and were augmented by group discussions, readings, and written assignments. The 45 hours of clinical practice provided opportunities to work directly with older adults residing in independent living, hospice and dementiacare facilities. Interviews with older adults were augmented with education geared toward older adults. The students also designed and implemented plans to improve the health and living conditions of the older adults. Examples included engaging students in senior programs in the local community, researching community resources, working for volunteer services, and implementing interventions to help older adults maintain themselves at home. The non-nursing group was not involved in any of the course content or activities; they completed the pre-and post-tests, at a three-month interval.
The comparison group was not provided any information regarding gerontological issues and never had any planned, formal contact with the intervention group in the campus.

\subsection{Procedures}

To recruit the nursing group, the study was announced to students in the gerontology course, which was required in the nursing program, during the first week of the semester. For the non-nursing group, flyers announcing the study were posted and distributed in large classrooms, and in a monthly electronic newsletter. Individuals who expressed a willingness to participate received the web address by email. Both the nursing and non-nursing groups were allowed on-line access to the pre-test during the first week of the semester. Email reminders of the post-test were sent to all participants during the 13th week of the semester.

\subsection{Measures}

The attitudes of the participants were assessed based on 1) the Attitudes toward Older People Scale, ${ }^{[26]}$ 2) journal entries regarding feelings toward older people, 3) Palmore's Facts on Aging Quiz (FAQ) for age bias ${ }^{[27]}$ at the time of the pre- and post-tests, and 4) individual background forms collected at the time of the pre-test. The Attitudes Toward Older People Scale assesses attitudes toward elderly people with respect to norms and individual differences, as well as stereotypes of and misconceptions about older people. The scale consists of 34 statements in total: 17 positive and 17 negative items on a 6 point Likert scale, yielding a sum of the positive and negative items ranging from 17 to 102 . For example, "It would probably be better if most old people lived in residential units with younger people," would be a positive statement, and "It would probably be better if most old people lived in residential units with people their own age," would be a negative statement. A higher score for positively worded statements indicated a positive attitude toward older people; a higher score for negatively worded statements indicated a negative attitude. Odd-even Spearman-Brown reliability coefficients for the negative scale were .76 and .73 for two groups of college students ( $\mathrm{N}=168$ and 128, respectively), and .83 for 186 older adults. ${ }^{[26,32]}$ Reliability coefficients for the positive scale were $.77, .66$, and .73 , respectively, for the same groups. The current study indicated Cronbach's alphas of .84 and .89 for the negative scale in the pre- and post-tests, respectively, and .69 and .85 for the positive scale.

The Facts on Aging Quizzes (FAQ I and II) were originally developed to measure students' knowledge about aging with binomial answer options (yes versus no ${ }^{[27]}$ and revised a multiple-choice format ${ }^{[33]}$ to measure pro- or anti-age bias from the answers. The multiple choice format reduced the 
effect of measurement error and the probability of answering correctly by guessing. The FAQ measures bias regarding common misconceptions about aging by analyzing responses to statements about physical, mental, and social facts. The FAQ consists of 25 items, each with one correct and three incorrect options. The incorrect options include a mixture of negative (anti-age), positive (pro-age), and neutral responses. A positive (pro-age) bias score was calculated as the ratio of the number of items answered positively (instead of correctly) to the total number of items that had positive-attitude response options (13 in FAQ I and 8 in FAQ II). A negative bias (anti-age) score was calculated as the ratio of the number of items answered negatively to the total number of items containing negative-attitude response options (18 in FAQ I and 16 in FAQ II). The current study found a reliability coefficient alpha of .70 for the anti-age bias scale and .47 for the pro-age bias scale.

Participants' positive and negative emotions toward older people were assessed by their writings and yielded the percentage of the emotional words in the text by using the Linguistic Inquiry and Word Count Program (LIWC). ${ }^{[34]}$ The LIWC2001 uses computer technology to assess an individual's linguistic style by the dictionary and is designed to "analyze written text on a word-by-word basis, and calculate the percentage of words in the text". [35] The LIWC program analyzes dimensions of psychological language including emotional, cognitive, physical, social, and structural component through the LIWC2007 dictionary. The LIWC2007 Dictionary is composed of approximately 4,500 words and word stems. The participants' spontaneous word use of the linguistic positive and negative emotional words was stable with 4-week interval: Test-retest correlations of 0.51 and 0.50 , high correlations for categories, respectively. ${ }^{[36]}$

According to Pennebaker, journal writing reflects the individual's emotional, cognitive, personal, and social status and serves as a bridge comparing feelings about phenomena to the realities of those phenomena. ${ }^{[35,37]}$ Thus, analysis of written thoughts is an efficient and effective method for studying the emotional, cognitive, structural, and process components of an individual's response to a topic. ${ }^{[37]}$

Participants in the present study were directed to write a journal of 400-500 words twice at the beginning and end of the semester, expressing their feelings, experiences, and beliefs about old people or aging, including positive and negative aspects. Participants in the present study were asked to fill out a personal background form, which included age, gender, ethnicity, primary language used at home, frequency of communication with older people, and experience of living with older people (defined as age 65 years or older).

\subsection{Analysis}

Both descriptive and inferential statistical analyses were performed using SPSS PC (Version 22.0). Descriptive statistics were used to show the characteristics of participants in both the nursing and non-nursing groups. A multivariate analysis of variance (MANOVA) with repeated measures was used to examine the effect of the gerontology course on attitudes toward aging, with the Kogan's scale, journal writings, and age bias questionnaire (FAQ) as dependent variables. The observed statistical power for each major (time or group) and interaction (time by groups) effect was between .91 and 1.0; partial eta-squared values were between .121 and .661. Univariate analysis of variance (ANOVA) with repeated measures followed to evaluate the impact of the gerontology course on each outcome measure over time and the group differences between the nursing and non-nursing groups over time. Differences were considered significant when the $p$ value of the time by group interaction effect was less than .05. The measures of the Kogan's Scale, FAQ, and journal writings did not satisfy the assumption of multivariate normality; however, MANOVA is known to be robust in the face of most violations of the normality assumption if the sample size is sufficiently large and the ratio of the two group sizes (the larger group to the smaller group) is less than 1.5. ${ }^{[38]}$ Therefore, the violation of the homogeneity assumption was considered to have minimal influence, if any, on the Type I error rate of significance testing. ${ }^{[38]}$ It was reasonably assumed that the participants within each group responded to each task independently from each other.

\section{ReSults}

\subsection{Sample characteristics}

Of the 197 students beginning the study, 147 (75\%) participants completed the entire process of the study: 82 in the intervention group and 65 in the comparison group. The average age of the participants was 24.5 years; about half were seniors at the university (see Table 1). Of the participants, $90 \%$ were female; $49 \%$ were white, most (84\%) spoke English at home, and approximately half had never lived with older adults. There were no significant differences in living experience, comfortable to communicate, and frequent communication with older adults between non-nursing and nursing groups (see Table 1).

\subsection{Positive and negative attitudes toward aging}

Overall, pre-test measures showed participants were more positive than negative in attitudes and feelings. Results of the Kogan's Scale had higher positive scores $(M=65.3$, SD $=7.88)$ than negative scores $(\mathrm{M}=43.0, \mathrm{SD}=10.36)$, and the difference was statistically significant $(t(146)=18.54$, $p<.001)$. Analysis of journal writings in feeling toward 
older people also indicated more positive $(\mathrm{M}=4.1, \mathrm{SD}=$ an indirect measurement, revealed more anti-age bias $(\mathrm{M}=$ 1.49) than negative emotion $(\mathrm{M}=2.9, \mathrm{SD}=1.77 ; t(146)=45.9 \%, \mathrm{SD}=15.61)$ than pro-age bias $(\mathrm{M}=25.2 \%, \mathrm{SD}=$ $6.04, p<.001)$. In contrast, age bias via the FAQ, which is $13.21, t(146)=-10.27, p<.001)$.

Table 1. Characteristics of participants for non-nursing and nursing groups $(\mathrm{N}=147)$

\begin{tabular}{|c|c|c|c|c|c|}
\hline \multirow{2}{*}{ Characteristics } & Total & Non-Nursing & Nursing & \multirow{2}{*}{$\chi^{2}$} & \multirow{2}{*}{$p$} \\
\hline & n (\%) & n (\%) & n (\%) & & \\
\hline Completion of the study & $147(74.6)$ & $65(72.2)$ & $82(76.6)$ & & \\
\hline Age, Mean (SD) & $24.5(5.81)$ & $25.1(6.11)$ & $23.9(5.52)$ & 6.10 & $.015^{*}$ \\
\hline Women & $132(89.8)$ & $53(81.5)$ & 79 (96.3) & 8.67 & $.003^{* *}$ \\
\hline \multicolumn{6}{|l|}{ Ethnicity: } \\
\hline White & $72(49.0)$ & $35(53.8)$ & $37(45.1)$ & \multirow{2}{*}{1.10} & \multirow{2}{*}{.293} \\
\hline Non-White & $75(51.0)$ & $30(46.2)$ & $45(54.9)$ & & \\
\hline \multicolumn{6}{|l|}{ School Year: } \\
\hline Freshman/Sophomore & $18(12.2)$ & $14(21.5)$ & $4(4.9)$ & \multirow{3}{*}{47.26} & \multirow{3}{*}{$.000 * *$} \\
\hline Junior/Senior & $105(71.4)$ & $28(43.1)$ & $78(95.1)$ & & \\
\hline Graduate & $24(16.3)$ & $23(35.4)$ & $0(0)$ & & \\
\hline \multicolumn{6}{|c|}{ Primary language used at home: } \\
\hline English & $124(84.4)$ & $49(75.4)$ & 75 (91.5) & \multirow{2}{*}{7.10} & \multirow{2}{*}{$.011^{*}$} \\
\hline Other & $23(15.6)$ & $16(24.6)$ & $7(8.5)$ & & \\
\hline \multicolumn{6}{|c|}{ Living experience with older adults: } \\
\hline No & $79(59.8)$ & $35(57.4)$ & $44(62.0)$ & \multirow{2}{*}{.29} & \multirow{2}{*}{.599} \\
\hline Yes & $53(40.2)$ & $26(42.6)$ & $27(38.0)$ & & \\
\hline \multicolumn{6}{|c|}{ Comfortable to communicate with older adults: } \\
\hline Rarely or somewhat & $72(49.0)$ & $36(55.4)$ & $36(43.9)$ & \multirow{2}{*}{1.91} & \multirow{2}{*}{.167} \\
\hline Always & $75(51.0)$ & $29(44.6)$ & $46(56.1)$ & & \\
\hline \multicolumn{6}{|c|}{ Frequent communication with older adults: } \\
\hline None to occasionally & $34(23.1)$ & $19(29.2)$ & $15(18.3)$ & \multirow{2}{*}{2.44} & \multirow{2}{*}{.118} \\
\hline Regularly & 113 (76.9) & $46(70.8)$ & 67 (81.7) & & \\
\hline
\end{tabular}

At the beginning of the study, there were significant differences in attitudes, feelings, and age bias between nursing and non-nursing students. The nursing group had statistically significantly higher scores for positive attitude $(F(1,146)=$ $5.32, p<.05)$ but lower scores in negative attitudes toward aging $(F(1,146)=4.17, p<.05)$, lower positive emotion $(F(1,146)=7.14, p<.01)$, and lower pro-age bias $(F(1,146)$ $=7.80, p<.01$ ) than the non-nursing group (see Table 2 ).

\subsection{Developing preferable attitudes toward older adults due to the gerontology course}

Multivariate analysis of variance with repeated measures applied simultaneously to the six dependent variables (Kogan's Attitude Scale scores, journal writing scores, and FAQ scores) showed a significant interaction between group and time $(\Lambda=.879, p<.01)$, indicating that exposure to the gerontology course affected the perceptions of the nursing group toward elderly people overall. There were no attempts to interpret the differences between groups (nursing versus non-nursing) and between times (pre- and post-test), because the interpretation of the main effects could be misleading when the interaction effect of group by time existed.

Attitude measures using Kogan's Scale: Results of ANOVA following the omnibus test of MANOVA showed significant effects between groups on positive attitude measured by the Kogan's Scale, but no significant interaction of group by time (see Table 3 ). The nursing group consistently scored higher in positive attitude $(F(1,146)=9.23, p<.01)$ than the non-nursing group over time. There was no reversal in the group difference over time $(F(1,146)=1.44, p>.05$, see Figure 2). However, the negative attitude scores from the Kogan's Scale showed a significant interaction of group by time $(F(1,146)=5.93, p<.05)$. The negative perception of the 
nursing group toward older people decreased significantly group showed a slight increase (see Figure 2). over time, while the negative perception of the non-nursing

Table 2. Comparison in attitudes, feelings, and bias toward older people between groups $(\mathrm{N}=147)$

\begin{tabular}{|c|c|c|c|c|c|c|}
\hline \multirow{2}{*}{ Predictor } & \multirow{2}{*}{ Group } & \multicolumn{3}{|c|}{ Pre-test } & \multirow{2}{*}{$F$} & \multirow{2}{*}{$p$} \\
\hline & & $\mathbf{n}$ & Mean & (SD) & & \\
\hline \multirow{3}{*}{$\begin{array}{l}\text { Kogan’s scale: } \\
\text { Positive attitude }\end{array}$} & Non-Nursing & 65 & 63.60 & $(8.43)$ & \multirow{3}{*}{5.32} & \multirow{3}{*}{$.023 *$} \\
\hline & Nursing & 82 & 66.57 & $(7.20)$ & & \\
\hline & Total & 147 & 65.26 & (7.88) & & \\
\hline \multirow{3}{*}{$\begin{array}{l}\text { Kogan's scale: } \\
\text { Negative attitude }\end{array}$} & Non-Nursing & 65 & 44.94 & (12.03) & \multirow{3}{*}{4.17} & \multirow{3}{*}{$.043 *$} \\
\hline & Nursing & 82 & 41.46 & (8.58) & & \\
\hline & Total & 147 & 43.00 & (10.36) & & \\
\hline \multirow{3}{*}{$\begin{array}{l}\text { Journal writing: } \\
\text { Positive emotion } \\
\text { (\%) }\end{array}$} & Non-Nursing & 65 & 4.42 & $(1.56)$ & \multirow{3}{*}{7.14} & \multirow{3}{*}{$.008^{* *}$} \\
\hline & Nursing & 82 & 3.77 & (1.36) & & \\
\hline & Total & 147 & 4.06 & (1.49) & & \\
\hline \multirow{3}{*}{$\begin{array}{l}\text { Journal writing: } \\
\text { Negative emotion (\%) }\end{array}$} & Non-Nursing & 65 & 2.93 & (1.70) & \multirow{3}{*}{.21} & \multirow{3}{*}{.649} \\
\hline & Nursing & 82 & 2.79 & $(1.82)$ & & \\
\hline & Total & 147 & 2.85 & (1.77) & & \\
\hline \multirow{3}{*}{$\begin{array}{l}\mathrm{FAQ}^{\dagger} \\
\text { Pro-aged bias } \\
(\%)\end{array}$} & Non-Nursing & 65 & 28.52 & (13.51) & \multirow{3}{*}{7.80} & \multirow{3}{*}{$.006 * *$} \\
\hline & Nursing & 82 & 22.51 & (12.49) & & \\
\hline & Total & 147 & 25.17 & (13.25) & & \\
\hline \multirow{3}{*}{$\begin{array}{l}\text { FAQ } \\
\text { Anti-aged bias } \\
(\%)\end{array}$} & Non-Nursing & 65 & 43.76 & (16.97) & \multirow{3}{*}{2.17} & \multirow{3}{*}{.143} \\
\hline & Nursing & 82 & 47.56 & (14.32) & & \\
\hline & Total & 147 & 45.88 & (15.61) & & \\
\hline
\end{tabular}

${ }^{*} p<.05,{ }^{* *} p<.01 ;{ }^{\dagger}$ Fact on aging quiz

Table 3. Changes in attitudes, feelings, and bias toward older people over a semester for groups $(\mathrm{N}=147)$

\begin{tabular}{|c|c|c|c|c|c|c|c|c|c|c|c|}
\hline \multirow{2}{*}{ Predictor } & \multirow{2}{*}{ Group (n) } & \multicolumn{2}{|c|}{ Pre-test } & \multicolumn{2}{|c|}{ Post-test } & \multicolumn{2}{|c|}{ Between group } & \multicolumn{2}{|l|}{ Time } & \multicolumn{2}{|c|}{ Time * Group } \\
\hline & & Mean & (SD) & Mean & $(S D)$ & $\boldsymbol{F}$ & $p$ & $\boldsymbol{F}$ & $p$ & $\boldsymbol{F}$ & $p$ \\
\hline \multirow{2}{*}{$\begin{array}{l}\text { Kogan's scale } \\
\text { Positive attitude }\end{array}$} & $\begin{array}{l}\text { Non-Nursing } \\
\text { (65) }\end{array}$ & 63.60 & (8.43) & 63.86 & (11.68) & \multirow{2}{*}{9.23} & \multirow{2}{*}{$.003^{* *}$} & \multirow{2}{*}{2.25} & \multirow{2}{*}{.136} & \multirow{2}{*}{1.44} & \multirow{2}{*}{.232} \\
\hline & Nursing (82) & 66.57 & $(7.20)$ & 68.94 & (10.57) & & & & & & \\
\hline \multirow{2}{*}{$\begin{array}{l}\text { Kogan's scale } \\
\text { Negative } \\
\text { attitude }\end{array}$} & $\begin{array}{l}\text { Non-Nursing } \\
\text { (65) }\end{array}$ & & & & & \multirow{2}{*}{12.08} & \multirow{2}{*}{$.001^{* *}$} & \multirow{2}{*}{1.68} & \multirow{2}{*}{.197} & \multirow{2}{*}{5.93} & \multirow{2}{*}{$.016^{*}$} \\
\hline & Nursing (82) & 41.46 & (8.58) & 38.04 & (11.43) & & & & & & \\
\hline \multirow{2}{*}{$\begin{array}{l}\text { Journal writing } \\
\text { Positive } \\
\text { emotion (\%) }\end{array}$} & $\begin{array}{l}\text { Non-Nursing } \\
\text { (65) }\end{array}$ & 4.42 & $(1.56)$ & 8.55 & (3.18) & \multirow{2}{*}{8.91} & \multirow{2}{*}{$.003^{* *}$} & \multirow{2}{*}{260.5} & \multirow{2}{*}{$.001^{* *}$} & \multirow[t]{2}{*}{.750} & \multirow{2}{*}{.388} \\
\hline & Nursing (83) & 3.77 & $(1.36)$ & 7.49 & $(2.57)$ & & & & & & \\
\hline \multirow{2}{*}{$\begin{array}{l}\text { Journal writing } \\
\text { Negative } \\
\text { emotion (\%) }\end{array}$} & $\begin{array}{l}\text { Non-Nursing } \\
\text { (65) }\end{array}$ & 2.93 & $(1.70)$ & 3.48 & (1.88) & \multirow[t]{2}{*}{5.27} & \multirow[t]{2}{*}{$.023^{*}$} & \multirow[t]{2}{*}{.64} & \multirow[t]{2}{*}{.425} & \multirow[t]{2}{*}{7.70} & \multirow[t]{2}{*}{$.006 * *$} \\
\hline & Nursing (83) & 2.79 & (1.82) & 2.48 & (1.67) & & & & & & \\
\hline \multirow{2}{*}{$\begin{array}{l}\mathrm{FAQ}^{\dagger} \text { Pro-aged } \\
\text { bias (\%) }\end{array}$} & $\begin{array}{l}\text { Non-Nursing } \\
\text { (65) }\end{array}$ & 28.52 & (13.51) & 28.28 & (9.33) & 4.74 & $.031 *$ & 4.58 & $.034 *$ & 5.38 & $.022 *$ \\
\hline & Nursing (83) & 22.51 & (12.49) & 28.42 & $(9.72)$ & & & & & & \\
\hline FAQ Anti-aged & $\begin{array}{l}\text { Non-Nursing } \\
\text { (65) }\end{array}$ & 43.76 & (16.97) & 48.37 & (10.92) & .543 & .462 & 2.80 & .096 & 3.99 & $.048 *$ \\
\hline Uids (70) & Nursing (83) & 47.56 & (14.32) & 47.15 & (8.70) & & & & & & \\
\hline
\end{tabular}

$* p<.05, * * p<.01 ;{ }^{\dagger}$ Fact on aging quiz 
Feelings toward older people obtained from journal writ- was no significant interaction of group by time $(F(1,146)$ ings: The nursing group consistently expressed significantly $=.75, p>.05)$. Conversely, negative emotions significantly fewer positive emotions about aging and older people in their journal writings than the non-nursing group $(F(1,146)=$ declined over time in the nursing group but increased in the $8.91, p<.01)$. Positive emotions doubled over time in both groups $(F(1,146)=260.50, p<.001$, see Figure 3), but there non-nursing group, resulting in a significant interaction effect of group by time $(F(1,146)=7.70, p<.01)$.
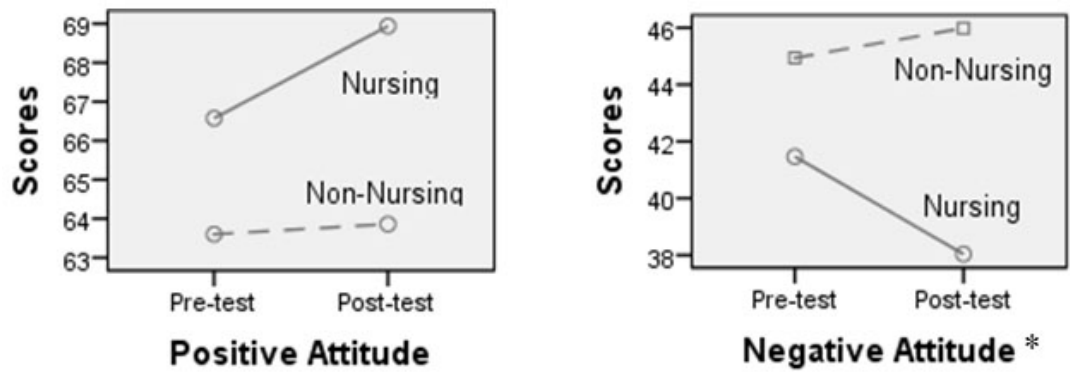

Figure 2. Kogan's Scale scores for positive and negative attitudes from pre- and post- tests for nursing and non-nursing groups

* Interaction effect between group and time $p<.05$.
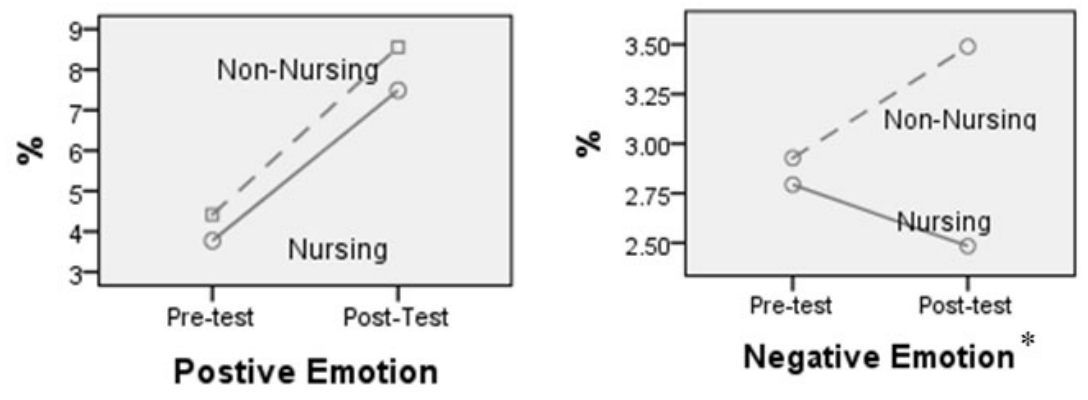

Figure 3. Mean percentages of positive and negative emotions from pre- and post- test journal writings for nursing and non-nursing groups

* Interaction effect between group and time $p<.05$.

Age bias measured by the FAQ: Results of the pre-test FAQ indicated that the nursing group had substantially less proage bias than the non-nursing group (see Table 3). However, the pro-age bias of the nursing group increased over time (see Figure 4), resulting in a significant interaction effect of group by time $(F(1,146)=5.38, p<.05)$. While the nursing group showed a slight decrease in anti-age bias over time, the non-nursing groups showed increased anti-age bias, also resulting in a marginally significant interaction effect of group by time $(F(1,146)=3.99, p<.05)$.
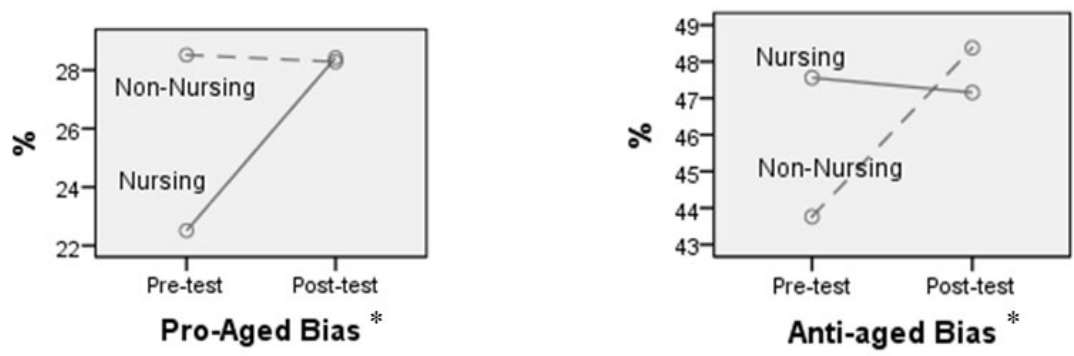

Figure 4. Mean percentages of pro- and anti-age bias from pre- and post- tests for nursing and non-nursing groups * Interaction effect between group and time $p<.05$. 


\section{Discussion}

The current study showed interesting results in measurement of attitudes. In the pre-test, the direct measures (Kogan's Attitude Scale and feelings from journal writings) of attitudes toward older people indicated more positive than negative expressions, while the indirect measures (age bias) gave opposing results with much greater anti-age bias than pro-age bias for the total sample and for each of the nursing and non-nursing groups. The findings from the indirect measures reveal that students perceive older people with significantly impaired physical, emotional and social functions more negatively than healthy older adults and believe common myths about aging. ${ }^{[39]}$ The inconsistent results by measurement suggest that multiple measures rather than a single measurement provide more in-depth information about the concept of attitudes. In the comparison of attitudes between nursing and non-nursing students, the nursing students showed a significant difference in several aspects including greater positive attitudes, less positive emotion/feelings, and less pro-age bias than their counterparts. This might be explained by the fact that nursing students consider/learn more overall aging phenomena in physical, emotional, and social aspects as opposed to one single aspect toward aging. However, with limited literature, this result should be further studied and supported.

The gerontology course did not appear to enhance the positive attitudes and feelings of the nursing students relative to their non-nursing peers. Although both nursing and nonnursing students exhibited increases in positive attitudes and feelings over time which is consistent with the literature, ${ }^{[11,13,40]}$ no significant interaction effect of time by group was shown. The improvement of positive attitudes in both groups over time may be attributed to the Hawthorne effect a change in behavior simply due to being studied. Therefore, measuring positive attitudes may not accurately reflect the effect of intervention. Results of the present study provide richer information about attitudes on aging and evidence that use of a comparison group and repeated measures in a study design provide a better understanding in evaluating the effect of education.

On the other hand, negative attitudes and feelings measured by the Kogan's scale and journal writings decreased significantly over time in the nursing group as compared to the non-nursing group, indicating that overall learning reduced negative attitudes about aging. This result is consistent with the findings of previous study, which showed that classes in gerontology reduced negative attitudes of students. ${ }^{[16]}$ These results are particularly encouraging, considering that nursing students and nurses working in hospital settings have generally unfavorable views of older adults..$^{[7,21]}$ Given the op- portunity to acquire knowledge about, gain experience with, and realize the importance of elder care, nursing students can replace negative attitudes with more objective (positive) views. The finding of a significant effect of the gerontology course on negative attitudes also supports the utility of the triadic theory of attitude ${ }^{[8]}$ which states that objective knowledge and experience of the common phenomena of aging can change people's cognition and feelings.

Meanwhile, the indirect measure of age bias (FAQ) showed a significant increase in pro-age bias and a decrease in anti-age bias over time in the nursing group, and a considerable increase in anti-age bias in the non-nursing group. The finding adds evidence supporting the literature that clinical placement and curricula focused on phenomena specific to older populations enhance attitudes toward older adults. ${ }^{[1,4,5]}$ Thus, an important conclusion of the current study is that separate gerontology courses in nursing curricula should be offered to provide a broader understanding of the aging population rather than focusing on pathological medical status. The increased anti-age bias of the non-nursing group over time might be explained as a result of the measurement method, which indirectly assessed age bias on the basis of knowledge. The FAQ counted only incorrect responses as bias. Participants in the non-nursing group might have guessed the correct answers in the pre-test, and then selected different answers in the post-test. As a result, pro-age bias decreased, and anti-age bias increased. However, the findings of the anti-age bias followed a similar trend to the findings of the negative aspects in attitudes and feelings. As no previous study used the FAQ and journal writings in a comparable manner, further studies of the use of multiple assessment methods are needed.

The current study has a few limitations. First, the convenient sampling of participants might include those who were probably interested in or motivated about the topic of the research study. Second, out of three instruments the questionnaire FAQ has low reliabilities which can have limited explanations even though it is used a part of total measurement. Last, some students in the non-nursing group could have been exposed to courses similar to the gerontological nursing course, which would be a confounding factor. Nevertheless, this study deepens an understanding of prospective nurses' perceptions toward older people by exploring the research phenomenon under a study design of repeated measures with a comparison group.

\section{Conclusions}

Results of the present study demonstrate a significant outcome of learning and experiencing common phenomena from a gerontology course on students' attitudes toward older 
adults, as measured by three instruments. The nursing students not only significantly reduced their negative attitudes toward the elderly, but showed a significant improvement in age bias, compared to the non-nursing group.

The multiple measures yielded a valuable result in understanding attitudes towards aging. Specifically, the indirect measure of attitudes through knowledge test seems to reflect the participants' unintentional or subconscious attitudes toward older people. Overall, the consistency among all three measures strengthens the validity of the results.
It is clear that multiple measures in a comparative research design provide more reliable results and compensate for the limitation of individual instruments. Further research of the effects of gerontology courses focusing on health and quality of life in older adults, using similar study designs and multiple measures, is recommended.

\section{CONFLicts OF InTEREST Disclosure}

The authors declare that there is no conflict of interest statement.

\section{REFERENCES}

[1] Koh LC. Student attitudes and educational support in caring for older people-a review of literature. Nurse Educ Pract. 2012; 12(1): 1620. PMid:21601527 http://dx.doi.org/10.1016/j.nepr. 20 11.04 .007

[2] McLafferty I, Morrison F. Attitudes towards hospitalized older adults. J Adv Nurs. 2004; 47(4): 446-53. PMid:15271164 http: //dx.doi.org/10.1111/j.1365-2648.2004.03122.x

[3] Rupp DE, Vodanovich SJ, Crede M. The multidimensional nature of ageism: construct validity and group differences. Journal of Social Psychology. 2005; 145(3): 335-62. PMid:15960004 http://dx . doi .org/10.3200/SOCP . 145 .3.335-362

[4] Swanlund S. Attitudes of baccalaureate nursing students toward older adults: a pilot study. Nurs Educ Perspect. 2012; 33(3): 181-3. http://dx.doi.org/10.5480/1536-5026-33.3.181

[5] King BJ, Roberts TJ, Bowers BJ. Nursing student attitudes toward and preferences for working with older adults. Gerontol Geriatr Educ. 2013; 34(3): 272-91. PMid:23383875 http://dx.doi.org/10. 1080/02701960.2012.718012

[6] Eymard AS, Douglas DH. Ageism among health care providers and interventions to improve their attitudes toward older adults: an integrative review. J Gerontol Nurs. 2012; 38(5): 26-35. PMid:22420518 http://dx.doi.org/10.3928/00989134-20120307-09

[7] Ferrario CG, Freeman FJ, Nellett G, et al. Changing nursing students' attitudes about aging: an argument for the successful aging paradigm. Educational Gerontology. 2008; 34(1): 51-66. http: //dx.doi.org/10.1080/03601270701763969

[8] Allport G. The historical background of modern social psychology. In: Lindzey $\mathrm{G}$, editor. Handbook of social psychology. 1: Theory and method. Reading, MA: Addison-Wesley; 1954. PMid:13204492

[9] Erwin P. Attitudes and persuasion. Hove [England], Philadelphia: Psychology Press; 2001.

[10] Kimuna SR, et al. College students' perceptions about older people and aging. Educational Gerontology. 2005; 31(7): 563-72. http://dx.doi.org/10.1080/03601270590962514

[11] Rodgers V, Gilmour J. Shaping student nurses' attitudes towards older people through learning and experience. Nurs Prax N Z. 2011; 27(3): 13-20. PMid:22375376

[12] Aud MA, Bostick JE, Marek KD, et al. Introducing baccalaureate student nurses to gerontological nursing. Journal of Professional Nursing. 2006; 22(2): 73-8. PMid:16564470 http://dx.doi .org /10.1016/j.profnurs.2006.01.005

[13] Fitzgerald JT, Williams BC, Halter JB, et al. Effects of a geriatrics interdisciplinary experience on learners' knowledge and at- titudes. Gerontology \& Geriatrics Education. 2006; 26(3): 17 28. PMid:16446269 http://dx.doi.org/10.1300/J021v26n0 3_02

[14] Flood MT, Clark RB. Exploring knowledge and attitudes toward aging among nursing and nonnursing students. Educational Gerontology. 2009; 35(7): 587-95. http://dx.doi .org/10.1080/03601 270802605333

[15] Allan LJ, Johnson JA. Undergraduate attitudes toward the elderly: The role of knowledge, contact and aging anxiety. Educational Gerontology. 2009; 35(1): 1-14. http://dx.doi.org/10.1080/03601 270802299780

[16] Snyder JR. The influence of instruction on college students' attitudes toward older adults. Gerontology \& Geriatric Education. 2005; 26(2): 69-79. http://dx.doi.org/10.1300/J021v26n02_05

[17] Burbank PM, Dowling-Castronovo A, Crowther MR, et al. Improving knowledge and attitudes toward older adults through innovative educational strategies. Journal of Professional Nursing. 2006; 22(2): 91-7. PMid:16564473 http://dx.doi.org/10.1016/j.profn urs. 2006.01.007

[18] Holroyd A, Dahlke S, Fehr C, et al. Attitudes toward aging: implications for a caring profession. J Nurs Educ. 2009; 48(7): 374-80. http://dx.doi.org/10.3928/01484834-20090615-04

[19] Olson MD. Assessing attitudes toward older adults and interest in gerontology among social work students. United States - Florida: Barry University School of Social Work; 2007.

[20] Paulson C. Educating for mindful perspectives on aging. J Nurs Educ. 2012; 51(6): 303-4. PMid:22658262 http://dx.doi.org/10. 39 28/01484834-20120522-01

[21] Higgins I, Van Der Riet P, Slater L, et al. The negative attitudes of nurses towards older patients in the acute hospital setting: a qualitative descriptive study. Contemp Nurse. 2007; 26(2): 225-37. http://dx.doi.org/10.5172/conu.2007.26.2.225

[22] Sofaer S, Shire A, Fortin J. GNEC evaluation brief: Multiplying change, ensuring all nurses learn to care well for older adults. 2013. Available from: http://www.aacn.nche.edu/geriatric-nur sing/GNEC-Evaluation-Brief .pdf

[23] Heise BA, Johnsen V, Himes D, et al. Developing positive attitudes toward geriatric nursing among Millennials and Generation Xers. Nurs Educ Perspect. 2012; 33(3): 156-61. http://dx.doi.org/1 $0.5480 / 1536-5026-33.3 .156$

[24] Berman A, Mezey M, Kobayashi M, et al. Gerontological nursing content in baccalaureate nursing programs: comparison of findings from 1997 and 2003. J Prof Nurs. 2005; 21(5): 268- 
75. PMid:16179239 http://dx.doi.org/10.1016/j.profnur s. 2005.07.005

[25] Thurston LL. Attitude can be measured. American Journal of Sociology. 1928; 33: 529-54. http://dx.doi.org/10.1086/214483

[26] KOGAN N. Attitudes toward old people in an older sample. J Abnorm Soc Psychol. 1961; 62: 616-22. http://dx.doi .org/10.10 $37 / \mathrm{h} 0048356$

[27] Palmore EB. The facts on aging quiz. 2nd ed. New York, NY: Springer Publishing Company; 1998. PMid:19598716

[28] Rosencranz HA, McNevin TE. A factor analysis of attitudes toward the aged. Gerontologist. 1969; 9: 55-9. PMid:5769675 http: //dx.doi.org/10.1093/geront/9.1.55

[29] Fraboni M, Salstone R, Hughes S. The Fraboni Scale of Ageism (FSA): An attempt at a more precise measure of ageism. Canadian Journal on Aging. 1990; 9: 56-66. http://dx.doi .org/10.1017 /S0714980800016093

[30] Christmas C, Park E, Schmaltz H, et al. A model intensive course in geriatric teaching for non-geriatrician educators. J Gen Intern Med. 2008; 23(7): 1048-52. PMid:18612742 http://dx .doi.org/10. 1007/s11606-008-0585-1

[31] StatPac10.1. StatPac Survey Software. Bloomington, MN: StatPac Inc.; 2005.

[32] KOGAN N. Attitudes toward old people: The development of a scale and an examination of correlates. J Abnorm Soc Psychol. 1961; 62: 44-54. http://dx.doi.org/10.1037/h0048053
[33] Harris DK, Changas PS, Palmore E. Palmore's first facts on aging quiz in a multiple-choice format. Educational Gerontology. 1996; 22(6): 15-9. http://dx.doi.org/10.1080/036012796022060 5

[34] LIWC2001. Linguistic Inquiry and Word Count (LIWC) Program. Mahwah, NJ: Erlbaum Publishers; 2001.

[35] Pennebaker JW, Francis ME, Booth RJ. LIWC2001 Manual. Mahwah, NJ: Erlbaum Publishers; 2003.

[36] Mehl MR, Pennebaker JW. The sounds of social life: a psychometric analysis of students' daily social environments and natural conversations. J Pers Soc Psychol. 2003; 84(4): 857-70. PMid:12703653 http://dx.doi.org/10.1037/0022-3514.84.4.857

[37] Pennebaker JW. What our words can say about us: Toward a broader language psychology. Psychological Science Agenda. 2002; 1: 8-9.

[38] Stevens JP. Applied multivariate statistics for the social sciences 4th ed. Mahwah, NJ: Lawrence Erlbaum; 2002.

[39] Thornton JE. Myths of aging or ageist stereotypes. Educational Gerontology. 2002; 28(4): 301-12. http://dx.doi.org/10.10 $80 / 036012702753590415$

[40] Rosher RB, Robinson S. The eden alternative: impact on student attitudes. Educational Gerontology. 2005; 31(4): 273-82. http: //dx.doi.org/10.1080/03601270590916777 